\title{
Smoke alarm ownership and house fire death rates in children
}

\author{
Carolyn DiGuiseppi, Ian Roberts, Leah Li
}

Residential fires are the second leading cause of unintentional injury death among children ages $1-14$ in the UK. ${ }^{1}$ Case-control data show that smoke alarms are associated with a substantial reduction in the risk of death in the event of a house fire, the protective effect being greatest in fires involving children under $5 .^{2}$ In the UK, the Home Office recommends that all homes are fitted with smoke alarms. Between 1988 and 1995, the Home Office ran annual television advertising campaigns in England and Wales to promote smoke alarm installation. We examined trends in childhood death rates from residential fires in relation to smoke alarm ownership.

\section{Methods and results}

From the Office for National Statistics we obtained anonymised death certificate records of all injury deaths between 1980 and 1995 for people aged 0-14 years in England and Wales. Records included age, sex, external cause of injury (E code), and year of death. Death rates for fires involving a "conflagration in a private dwelling" (E code 890) were calculated using published census denominator data. Unpublished smoke alarm prevalence data for 1980 to 1995 for England and Wales were obtained from the Home Office. Smoke alarm prevalence figures are obtained from periodic surveys of a random sample of households in England and Wales using interviewer administered questionnaires. The relation between house fire death rates and smoke alarm prevalence was examined using Poisson regression modelling. ${ }^{3}$ Death rate was the dependent variable, with smoke alarm prevalence (A) and year (Y) the explanatory variables. The expected

Roberts.

Accepted for publication 24 June 1998

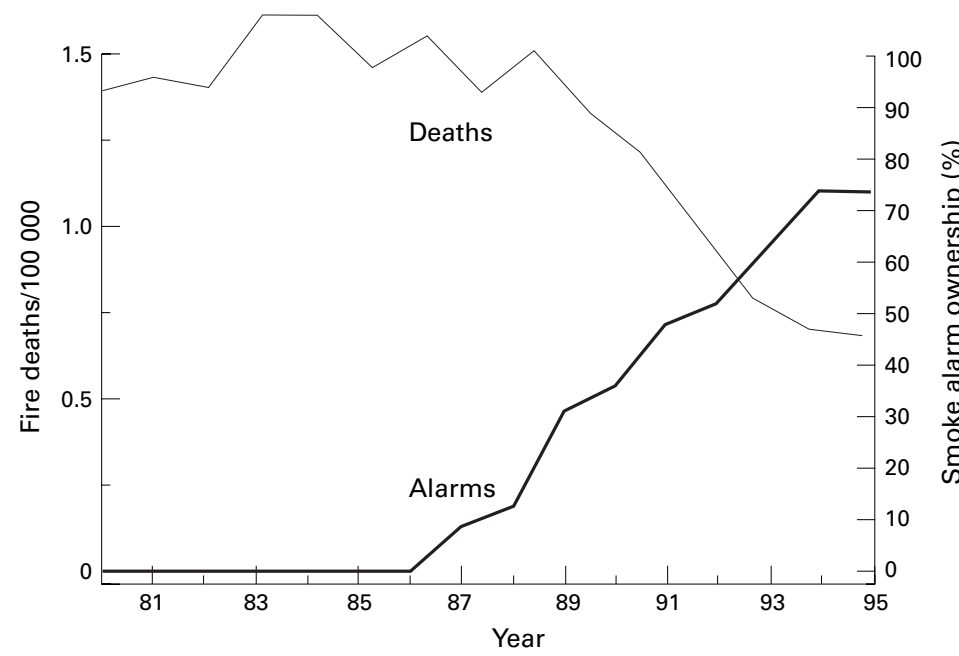

Figure 1 Trends in fire death rates in children aged 0-4 years (3 year moving average) and smoke alarm ownership. death rate $(\mathrm{F})$ was modelled by a $\log$ linear equation of the form $\log (\mathrm{F})=\beta_{0}+\beta_{1} \mathrm{~A}+\beta_{2} \mathrm{Y}$. Models were checked using normal quantile plots and residuals versus fitted value plots. Because lone parenthood, poor housing condition (for example, overcrowding), and financial difficulties are risk factors for residential fires, ${ }^{4}$ the annual proportions of lone parent families and numbers of families living in temporary accommodation (as a proxy for poor housing condition and financial difficulties) were included in the model as potential confounding variables. "Temporary accommodation" comprises temporary bed and breakfast accommodation provided to homeless families awaiting placement in permanent local government owned housing.

Figure 1 shows the fire death rates for children aged $0-4$ in relation to smoke alarm ownership. After fitting the crude model, only the smoke alarm variable was significant. On the basis of the model, a $10 \%$ increase in alarm ownership was associated with a $13 \%$ reduction in the risk of fire death among children aged $0-4(\mathrm{RR}=0.87 ; 95 \% \mathrm{CI} 0.81$ to 0.94$)$. In this age group, controlling for trends in lone parenthood and households in temporary accommodation strengthened the association with smoke alarms $(R R=0.56 ; 95 \%$ CI 0.39 to 0.80$)$. For children aged 5-14 years, in the crude model, the association between alarm ownership and fire death rates was weaker and not significant $(\mathrm{RR}=0.92 ; 95 \% \mathrm{CI} 0.83$ to 1.03$)$. When the relation between fire death rates in children aged 5-14 years and smoke alarm ownership was adjusted for confounding, the association was stronger than in the crude model, but was still consistent with the play of chance $(\mathrm{RR}=0.64 ; 95 \%$ CI 0.39 to 1.06$)$.

\section{Comment}

Because of the ecological nature of this study, the observed association between smoke alarm prevalence and fire death rates must be interpreted with caution. In particular, it is conceivable that factors apart from smoke alarms, such as reduced risk of fire occurrence or severity, or reduced case-fatality rates, may have accounted for some of the decline in childhood fire death rates between 1987 and 1995. The number of dwelling fires reported to the Fire Brigade each year has remained stable since $1986^{5}$; as the Fire Brigade is called preferentially to more serious fires, ${ }^{5}$ these figures suggest that the observed declines in fire deaths are unlikely to be result from declines in the incidence of fires or of serious fires. It is possible that changes in product safety or building regulations, for example, 
reduced fabric flammability, have decreased the likelihood that a given fire will result in a casualty. Reduced death after injury because of improvements in emergency services and medical care may also have contributed to declines in fire death rates. Although we cannot exclude these as potential contributors, it is not clear why such changes would have a greater effect on children aged $0-4$ than those aged $5-14$. On the other hand, the number of fires discovered by smoke alarms increased sixfold between 1988 and $1995 . .^{5}$ Such fires were associated with a fatal casualty rate of 4 of 1000 fires, compared with 10 of 1000 fires for those discovered by other means. ${ }^{5}$ These ecological data provide additional support for our findings.

Temporal trends in childhood fire deaths in the UK are consistent with results from case control studies suggesting a protective effect of smoke alarms. The finding that the association between alarm prevalence and deaths was strongest for children aged $0-4$ is also consistent. Our data suggest that efforts to increase smoke alarm ownership have the potential to substantially reduce fire death rates in children.

Funding: Dr Carolyn DiGuiseppi is funded by Camden and Islington Health Authority. Dr Ian Roberts and Ms Leah Li are funded by the Sir Siegmund Warburg Charitable Trust. Conflicts of interest: none.
KEY POINTS

- Fires are the second leading cause of accidental death in children ages 1-14 in the UK.

- Case-control data show that smoke alarms are associated with a reduced risk of death, particularly for children under five.

- Trends in childhood fire deaths are consistent with results from case-control studies, suggesting a protective effect of smoke alarms.

- Results from Poisson regression modelling show that a $10 \%$ increase in alarm ownership is associated with a $13 \%$ reduction in the risk of fire death among children aged $0-4$ years.

1 DiGuiseppi C, Roberts I. Injury mortality among children and teenagers in England and Wales, 1992. Injury $97 ; 3: 47-9$.

2 Runyan CW, Bangdiwala SI, Linzer MA, et al. Risk factors for fatal residential fires. N Engl f Med 1992;37:859-63.

3 Frome EL. The analysis of rates using Poisson regression models. Biometrics 1983;39:665-74.

4 Budd T, Mayhew P. Fires in the home in 1995: results from the British Crime Survey. Home Office Statistical Bulletin 9/97. London: Government Statistical Service, 1997.

5 Collier P, Watson L. Summary fire statistics: United Kingdom 1996. Home Office Statistical Bulletin 1/98. London: Government Statistical Service, 1998. 